\title{
Fruit and vegetable consumption and its recommended intake associated with sociodemographic factors: Thailand National Health Examination Survey III
}

\author{
Warapone Satheannoppakao 1,*, Wichai Aekplakorn ${ }^{2}$ and Mandhana Pradipasen ${ }^{1}$ \\ 'Department of Nutrition, Faculty of Public Health, Mahidol University, 420/1 Rajvithi Road, Rachathewi District, \\ Bangkok 10400, Thailand: ${ }^{2}$ Community Medicine Center, Faculty of Medicine, Ramathibodi Hospital, Mahidol \\ University, Bangkok, Thailand
}

Submitted 8 February 2008: Accepted 23 March 2009: First published online 19 May 2009

\begin{abstract}
Objective: To examine the fruit and vegetable consumption in Thailand, the percentage of Thais meeting recommended intakes and the association with sociodemographic factors.

Design: Cross-sectional survey with a stratified, three-stage, cluster probability sampling design.

Setting: Community-dwelling men and women participating in the Thailand National Health Examination Survey III.

Subjects: A total of 39290 individuals aged $\geq 15$ years were interviewed using a questionnaire to obtain information on sociodemographic characteristics and fruit and vegetable consumption. Daily fruit and vegetable consumption was estimated through the use of a short semi-qualitative FFQ.

Results: Overall, participants had average frequencies of fruit and vegetable consumption equal to 4.56 and $5.97 \mathrm{~d} /$ week, respectively. Average daily number of servings of fruit, vegetables and fruit plus vegetables were 1.46, 1.78 and 3.24, respectively. Intake amounts of fruit, vegetables and fruit plus vegetables varied by marital status and region, and were lower among males (except for vegetable intake), those of older age, those with low educational attainment, those with low monthly household income and those living in a rural area. Only $1 / 3,1 / 4$ and $1 / 4$ of the population consumed the recommended $\geq 2, \geq 3$ and $\geq 5$ servings/d for fruit, vegetables and fruit plus vegetables. Sociodemographic factors related to meeting the recommended intake of $\geq 5$ servings/ $d$ for fruit plus vegetables included being female $(\mathrm{OR}=1 \cdot 13)$ and household income $\geq 50000 \mathrm{Baht} / \mathrm{month}(\mathrm{OR}=1 \cdot 66)$.

Conclusions: The amounts of fruit and vegetables consumed by Thai participants were far below the level of current recommendations. Public education and campaigns on adequate consumption of fruits and vegetables should be targeted more towards low socio-economic groups.
\end{abstract}

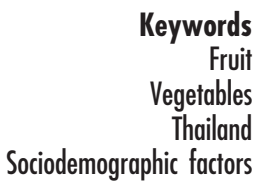

An adequate consumption of fruit and vegetables provides a number of benefits for health. Previous studies have revealed that adequate fruit and vegetable consumption has protective effects against and/or may delay the onset of critical chronic and deteriorating diseases and conditions $^{(1-8)}$. This benefit results from the rich content of vitamins, minerals, fibre and phytochemicals in these food groups. Without doubt, low fruit and vegetable intake can lead to undesirable health outcomes. According to the 2002 WHO world health report, up to $2 \cdot 7$ million deaths annually are caused by low fruit and vegetable consumption ${ }^{(9)}$.

Although the advantages of fruit and vegetable intake in sufficient amounts are recognized, people in both developed and developing countries still have inadequate fruit and vegetable intake ${ }^{(9,10)}$. As indicated by National Nutrition Survey reports (1986 and 1995), the population in Thailand - like in other countries - consumes low amounts of fruit and vegetables ${ }^{(11,12)}$. However, their current patterns of fruit and vegetable consumption are mostly unknown.

As recommended in the WHO 'fruit and vegetable promotion' campaign launched in 2003, an individual should eat at least 5 servings or $400 \mathrm{~g}$ of fruit and vegetables daily ${ }^{(13)}$. Several studies have reported the association of fruit and vegetable intake with sociodemographic factors $^{(14-20)}$; however, the results are inconsistent. This drew our attention to the questions of whether the frequencies 
and amounts of fruit and vegetables consumed by Thais differ from the current international recommendation; and whether meeting the recommended consumption is associated with sociodemographic characteristics. Therefore the objectives of the present study were to examine fruit and vegetable consumption and its recommended intake in association with sociodemographic factors among Thai adults. Regarding fruit and vegetable consumption, we assessed frequencies and amounts of fruit and vegetable consumed and estimated the percentage of Thais meeting the recommended intakes of fruit, vegetables and fruit plus vegetables.

\section{Methods}

\section{Research design}

The Thailand National Health Examination Survey III (NHESIII) is a nationally representative cross-sectional survey using multistage, stratified cluster sampling. Detailed methods are described elsewhere ${ }^{(21)}$. The final collected sample comprised 39290 individuals, who were representative of Thai population aged 15 years and older. The study was approved by the Ethical Review Committee for Research in Human Subjects, Ministry of Public Health. All participants provided written informed consent.

\section{Instrument}

An interview questionnaire was designed and tested before the survey. It collected three types of information as follows.

1. Sociodemographic characteristics: questions covered information on participants' gender, age, current marital status, highest education level attained, household monthly income, region and residential area.

2. Fruit and vegetable intake: a short semi-qualitative FFQ with four questions was carried out to assess the frequency (number of days per week) and amount (standard serving size) of fruit and vegetables consumed in one week over the past 12 months. One serving size of fruit was defined as 6-8 pieces of ripe papaya, water melon or pineapple, 1 banana, 1 tangerine, 4 rambutans, $\frac{1}{2}$ cup of no-added-sugar processed fruit, $\frac{1}{2}$ cup of canned fruit or $\frac{1}{2}$ cup of $100 \%$ fruit juice. A serving of vegetables referred to $\frac{1}{2}$ cup of cooked leafy vegetables, 1 cup of raw green leafy vegetables, $\frac{1}{2}$ cup of tomato, carrot, pumpkin, cabbage, beans or white onion, or $\frac{1}{2}$ cup of $100 \%$ vegetable juice.

3. Pictorial sheets: pictorial sheets consisted of (i) pictures of fruits and vegetables in one serving size and (ii) a picture of the standard measuring cup ( 1 cup $=240 \mathrm{ml})$.

\section{Data collection}

Data collection was conducted from January to April 2004 by trained research assistants.
The eligible participants in the selected households were invited to participate and interviewed. In collecting information on fruit and vegetable intake, the trained interviewers asked each participant to indicate frequencies and amounts of fruit and vegetables consumed and subsequently to clarify the information interviewed. Pictorial sheets were used as the aids to estimate serving size of fruits and vegetables eaten.

\section{Statistical analyses}

Data analyses were performed with the Stata/MP 9.2 for Windows statistical software package (StataCorp, College Station, TX, USA) to take into consideration the complex sampling design. Proper weighting variables transformed the data set into a nationally representative sample. Descriptive statistics were calculated to describe the participants' characteristics, fruit and vegetable consumption, and their relationships. Due to the skewed distribution of data, nonparametric tests were carried out. Median differences among three or more subgroups of sociodemographic variables in fruit and vegetable consumption were assessed using the Kruskal-Wallis test. Then the Wilcoxon rank-sum test was conducted for post hoc comparisons.

In the present study, the total quantity of vegetables and/or fruits was calculated by multiplying the weekly frequency by the amount consumed and then dividing by 7 in order to give the number of daily intake servings. The daily recommended intake levels were at least 5 servings for fruit plus vegetables, 2 servings for fruit and 3 servings for vegetables. Multivariate logistic regression analysis with backward elimination for likelihood ratio was utilized to determine the associations of several sociodemographic factors with the three outcome variables in separate models (i.e. meeting recommended intake amounts of fruit, vegetables and both fruit and vegetables). The best-fit models with significant associated variables for each outcome are reported. Statistical outcomes were considered significant at $P<0 \cdot 05$.

\section{Results}

\section{Sociodemographic characteristics}

Of the 39290 participants, $51 \cdot 8 \%$ were female. Average age in years was $39 \cdot 13(\mathrm{SD} 0 \cdot 18), 40 \cdot 44(\mathrm{SD} 0 \cdot 19)$ and $39 \cdot 80(\mathrm{SD}$ $0 \cdot 15$ ) for males, females and the total sample, respectively. Almost $70 \%$ were married. Two-thirds of participants graduated from an elementary school. Nearly two-thirds of them had household income lower than 10000 Baht/ month, with an average of $10176 \mathrm{Baht} / \mathrm{month}$. One-third resided in the central part of Thailand, followed by the north-east and the north. Over half lived in an urban area.

\section{Fruit and vegetable consumption}

Only $36.5 \%$ of Thais consumed fruit daily, and $68 \cdot 0 \%$ consumed vegetables daily. The average number of days 
on which fruit and vegetables were eaten per week was 4.56 (SD 2.17, median 4.00) and 5.97 (SD 1.70, median $7 \cdot 00)$, respectively.

Participants on average consumed 1.46, 1.78 and $3 \cdot 24$ daily servings of fruit, vegetables and fruit plus vegetables, respectively (Table 1). Women consumed significantly more fruit and fruit plus vegetables than did men. Fruit and vegetable intake seemed to decline with advancing age, but increased with educational level and monthly household income. Furthermore, average amounts of fruit and vegetable intake varied by marital status and region. Interestingly, participants dwelling in urban areas had significantly higher intakes of fruit and vegetables than did those in rural areas.

Only $1 / 3,1 / 4$ and $1 / 4$ of participants reached the minimum daily recommended intake levels for fruit, vegetables and fruit plus vegetables, respectively (Table 2). More women followed fruit and fruit plus vegetable intake recommendations than did men. The percentage of participants reaching the fruit and vegetable recommendations varied by region and residential area, and was lower among those with older age, lower educational level and monthly household income, and among married participants.

\section{Sociodemographic factors associated with fruit and vegetable consumption}

Table 3 illustrates the sociodemographic factors associated with meeting the recommended intakes for fruit, vegetables and both. The most important factors for meeting the fruit intake recommendation were being female $(\mathrm{OR}=1 \cdot 46)$, having educational level of secondary and vocation school $(\mathrm{OR}=1 \cdot 42)$ and household income of $\geq 50000$ Baht/ month $(\mathrm{OR}=1 \cdot 60)$. Significant sociodemographic characteristics associated with meeting the recommendation for vegetable consumption included household income of $\geq 50000 \mathrm{Baht} / \mathrm{month}(\mathrm{OR}=1 \cdot 45)$ and living in Bangkok $(\mathrm{OR}=1 \cdot 52)$. Furthermore, female gender $(\mathrm{OR}=1 \cdot 13)$ and household income of $\geq 50000 \mathrm{Baht} /$ month $(\mathrm{OR}=1 \cdot 66$ ) were strongly related to recommended levels of fruit and vegetable consumption. As the age of the participants increased, the less likely they were to meet the recommended fruit and vegetable intake amounts.

\section{Discussion}

The present study reveals that the majority of Thai individuals consumed less fruit and vegetables daily than the recommended intake levels. Only $36.5 \%$ and $68.0 \%$ of Thais ate fruit and vegetables on a daily basis. Furthermore, average daily servings for fruit, vegetables and fruit plus vegetables were $1 \cdot 46,1 \cdot 78$ and $3 \cdot 24$, respectively. In comparison with data obtained from the National Nutrition Survey III (1986) and IV (1995) ${ }^{(11,12)}$, the current study shows that Thais have increased their fruit and vegetable intake slightly. From the National Nutrition
Survey III, food intake data collected using the weighing method and $24 \mathrm{~h}$ dietary recall showed that Thais consumed $1 \cdot 06,1.33$ and $2 \cdot 40$ servings daily for fruit, vegetables and fruit plus vegetables, respectively ${ }^{(11)}$. The National Nutrition Survey IV reported only 0.96 servings for fruit, 1.42 for vegetables and 2.38 for fruit plus vegetables consumed each day ${ }^{(12)}$.

When interpreting results, differences in dietary assessment methods may make a direct comparison of average intake amounts among studies problematic. We realize this problem and thereby give its inclusive picture as a trend in fruit and vegetable consumption. In the current study, a short FFQ was used for assessing the quantity of fruit and vegetables consumed daily on account of two main reasons: (i) it provides outcomes quite similar to those obtained from other different dietary assessment methods ${ }^{(22,23)}$; and (ii) this method can easily and appropriately be used for dietary assessment of a very large population group.

Diversities in the median amounts and percentage of individuals meeting recommendations for fruit, vegetable and fruit plus vegetable intakes are explained by sociodemographic characteristics. Consistent with previous studies, we found that gender significantly affected the intakes of fruit and vegetables ${ }^{(14-18)}$. Women are likely to eat more fruit than men ${ }^{(14-18)}$. For vegetable intake, however, the present findings are inconsistent with others $^{(14-16)}$, which found that women had higher intakes of vegetables compared with men. Possibly, women have a greater health concern than men ${ }^{(17)}$. In contrast with O'Brien et al. $^{(18)}$, who evaluated the compliance with dietary guidelines for vegetable and fruit intake in Irish adults, the mean intake of vegetables among male respondents of the present survey was higher than that among females, 149 v. $132 \mathrm{~g} / \mathrm{d}$, respectively. This may be due to the fact that men eat food in larger quantities. As in Giskes et al.'s study ${ }^{(19)}$, our data showed that women and men consumed similar amounts of vegetables. Analysed outcomes also revealed that being female is one of the significant factors for complying with the recommended levels of fruit $(\mathrm{OR}=1 \cdot 46)$ and fruit plus vegetable $(\mathrm{OR}=1 \cdot 13)$ intake.

Studies conducted by Thompson et al. ${ }^{(16)}$ and Ball et $a l^{(20)}$ revealed an increasing trend of fruit and vegetable intake with advancing age. On the contrary, our findings indicated that older age groups were more likely to consume lesser amounts of fruit, vegetables and fruit plus vegetables than younger age groups. Natural deteriorating changes as one gets older and health conditions may be important causes of the low consumption of fruit and vegetables. These may reflect difficulty in reaching fruit and vegetable sources, reduction of appetite for food, or inconvenience in preparing food. In relation to marital status, those who were single tended to consume larger amounts of fruit and vegetable than those who were married or widow/divorced/separated. These findings 


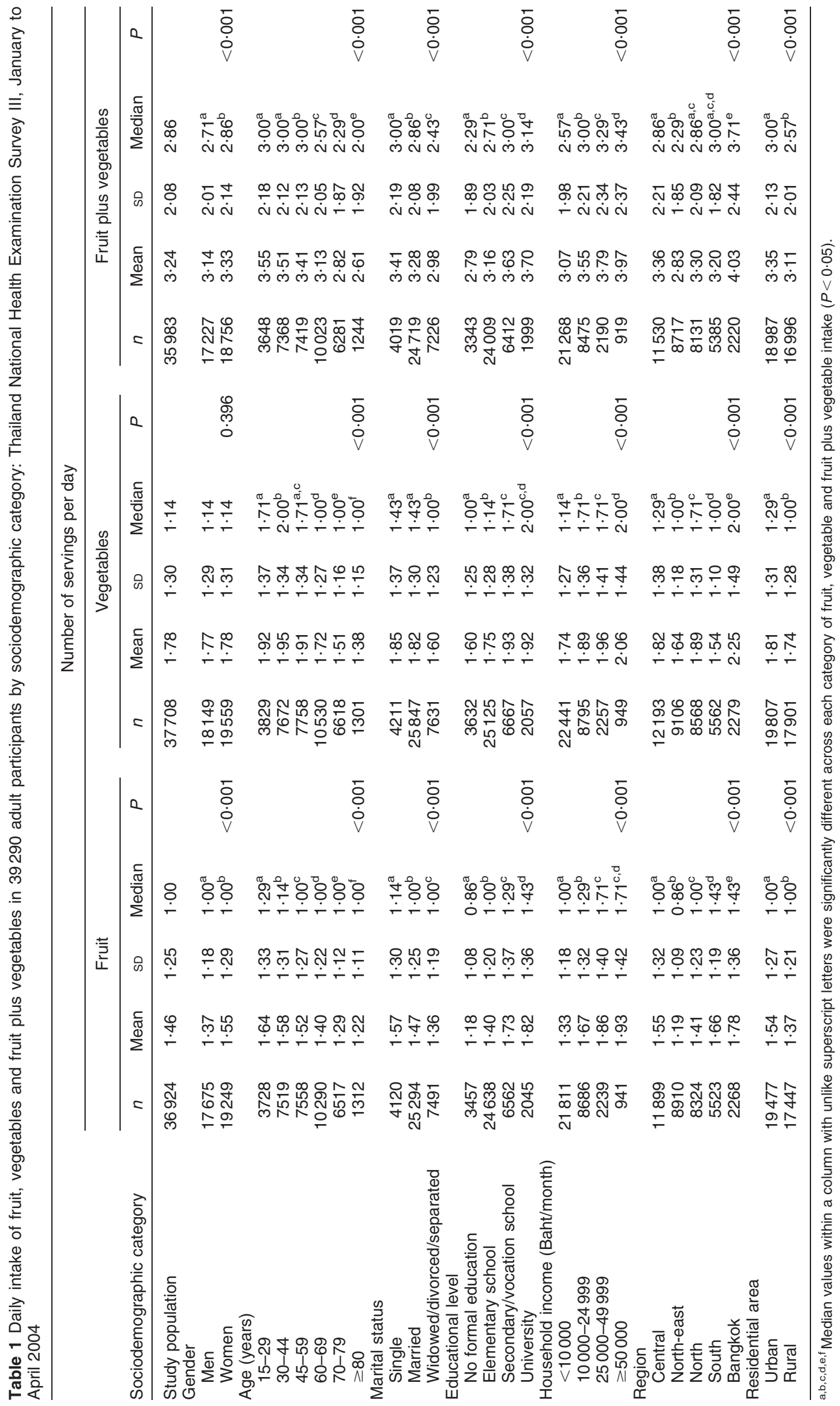


Table 2 Percentage meeting daily recommended levels of fruit, vegetable and fruit plus vegetable intake among 39290 adult participants by sociodemographic category*: Thailand National Health Examination Survey III, January to April 2004

\begin{tabular}{|c|c|c|c|c|c|c|c|c|c|}
\hline \multirow[b]{3}{*}{ Sociodemographic category } & \multicolumn{9}{|c|}{ Percentage of participants meeting } \\
\hline & \multicolumn{3}{|c|}{$\begin{array}{l}\text { Fruit recommendation } \\
\quad(\geq 2 \text { servings/d) }\end{array}$} & \multicolumn{3}{|c|}{$\begin{array}{l}\text { Vegetable recommendation } \\
\quad(\geq 3 \text { servings/d) }\end{array}$} & \multicolumn{3}{|c|}{$\begin{array}{l}\text { Fruit plus vegetable recommendation } \\
\qquad(\geq 5 \text { servings } / d)\end{array}$} \\
\hline & Male & Female & Total & Male & Female & Total & Male & Female & Total \\
\hline Study population & 31.5 & $39 \cdot 1$ & $35 \cdot 4$ & $27 \cdot 4$ & $26 \cdot 5$ & $26 \cdot 9$ & $25 \cdot 4$ & $27 \cdot 7$ & $26 \cdot 6$ \\
\hline \multicolumn{10}{|l|}{ Age (years) } \\
\hline $15-29$ & $34 \cdot 2$ & $43 \cdot 3$ & $38 \cdot 7$ & $28 \cdot 2$ & $25 \cdot 5$ & $26 \cdot 8$ & $27 \cdot 8$ & $28 \cdot 5$ & $28 \cdot 1$ \\
\hline $30-44$ & $31 \cdot 0$ & $39 \cdot 1$ & $35 \cdot 1$ & $28 \cdot 4$ & $28 \cdot 6$ & $28 \cdot 5$ & $24 \cdot 7$ & $28 \cdot 8$ & $26 \cdot 8$ \\
\hline $45-59$ & $29 \cdot 6$ & $38 \cdot 2$ & $34 \cdot 1$ & $28 \cdot 4$ & $28 \cdot 1$ & $28 \cdot 2$ & $24 \cdot 3$ & $27 \cdot 5$ & $26 \cdot 0$ \\
\hline $60-69$ & $30 \cdot 1$ & $33 \cdot 3$ & $31 \cdot 8$ & $22 \cdot 4$ & $23 \cdot 7$ & $23 \cdot 1$ & $23 \cdot 4$ & $25 \cdot 1$ & $24 \cdot 3$ \\
\hline $70-79$ & $28 \cdot 8$ & $30 \cdot 7$ & $29 \cdot 8$ & $19 \cdot 4$ & $20 \cdot 0$ & $19 \cdot 7$ & $21 \cdot 4$ & $22 \cdot 3$ & $21 \cdot 9$ \\
\hline$\geq 80$ & $26 \cdot 3$ & $29 \cdot 5$ & $28 \cdot 2$ & $19 \cdot 9$ & $17 \cdot 7$ & $18 \cdot 6$ & $21 \cdot 3$ & $23 \cdot 7$ & $22 \cdot 7$ \\
\hline \multicolumn{10}{|l|}{ Marital status } \\
\hline Single & $33 \cdot 1$ & $41 \cdot 2$ & $37 \cdot 3$ & $28 \cdot 1$ & $25 \cdot 2$ & $26 \cdot 6$ & $28 \cdot 3$ & $29 \cdot 1$ & $28 \cdot 7$ \\
\hline Married & $32 \cdot 4$ & $38 \cdot 8$ & $35 \cdot 7$ & $27 \cdot 6$ & $27 \cdot \overline{2}$ & $27 \cdot 4$ & $25 \cdot 9$ & $28 \cdot 0$ & $27 \cdot 0$ \\
\hline Widowed/divorced/separated & $24 \cdot 1$ & $40 \cdot 6$ & $33 \cdot 0$ & $23 \cdot 3$ & $28 \cdot 5$ & $26 \cdot 1$ & $20 \cdot 3$ & $27 \cdot 9$ & $24 \cdot 4$ \\
\hline \multicolumn{10}{|l|}{ Educational level } \\
\hline No formal education & $27 \cdot 1$ & $32 \cdot 8$ & $30 \cdot 0$ & $24 \cdot 2$ & $31 \cdot 3$ & $27 \cdot 8$ & $23 \cdot 1$ & $27 \cdot 2$ & $25 \cdot 2$ \\
\hline Elementary school & $29 \cdot 0$ & $35 \cdot 0$ & $32 \cdot 0$ & $27 \cdot 0$ & $26 \cdot 6$ & $26 \cdot 8$ & $23 \cdot 7$ & $25 \cdot 0$ & $24 \cdot 4$ \\
\hline Secondary/vocation school & $37 \cdot 0$ & $50 \cdot 1$ & $43 \cdot 7$ & $29 \cdot 8$ & $28 \cdot 9$ & $29 \cdot 3$ & $29 \cdot 1$ & $34 \cdot 8$ & $32 \cdot 0$ \\
\hline University & 38.5 & $54 \cdot 5$ & $46 \cdot 7$ & $31 \cdot 8$ & $28 \cdot 9$ & $30 \cdot 3$ & $28 \cdot 7$ & $36 \cdot 0$ & $32 \cdot 4$ \\
\hline \multicolumn{10}{|c|}{ Household income (Baht/month) } \\
\hline$<10000$ & $28 \cdot 8$ & $34 \cdot 6$ & $31 \cdot 8$ & $26 \cdot 1$ & $24 \cdot 9$ & $25 \cdot 5$ & $23 \cdot 5$ & $25 \cdot 0$ & $24 \cdot 3$ \\
\hline $10000-24999$ & $36 \cdot 0$ & $46 \cdot 0$ & $41 \cdot 1$ & $29 \cdot 3$ & $28 \cdot 6$ & $28 \cdot 9$ & $29 \cdot 0$ & $31 \cdot 7$ & $30 \cdot 4$ \\
\hline $25000-49999$ & 41.5 & $54 \cdot 1$ & $48 \cdot 0$ & $33 \cdot 6$ & $34 \cdot 1$ & $33 \cdot 8$ & $30 \cdot 9$ & $38 \cdot 1$ & $34 \cdot 6$ \\
\hline$\geq 50000$ & $41 \cdot 0$ & $61 \cdot 6$ & $51 \cdot 5$ & $38 \cdot 8$ & $34 \cdot 0$ & $36 \cdot 3$ & $35 \cdot 8$ & $44 \cdot 5$ & $40 \cdot 2$ \\
\hline \multicolumn{10}{|l|}{ Region } \\
\hline Central & $36 \cdot 7$ & $45 \cdot 0$ & $40 \cdot 9$ & $30 \cdot 8$ & $29 \cdot 1$ & $30 \cdot 0$ & $29 \cdot 5$ & $33 \cdot 1$ & $31 \cdot 3$ \\
\hline North-east & $24 \cdot 4$ & $29 \cdot 4$ & $27 \cdot 0$ & $23 \cdot 4$ & $23 \cdot 8$ & $23 \cdot 6$ & $20 \cdot 2$ & $20 \cdot 7$ & $20 \cdot 4$ \\
\hline North & $32 \cdot 6$ & $37 \cdot 8$ & $35 \cdot 2$ & $29 \cdot 6$ & $27 \cdot 9$ & $28 \cdot 8$ & $28 \cdot 0$ & $29 \cdot 3$ & $28 \cdot 6$ \\
\hline South & $37 \cdot 7$ & $51 \cdot 7$ & 44.9 & $23 \cdot 4$ & $21 \cdot 4$ & $22 \cdot 4$ & $24 \cdot 5$ & $30 \cdot 4$ & $27 \cdot 5$ \\
\hline Bangkok & $36 \cdot 0$ & $49 \cdot 4$ & $42 \cdot 8$ & $42 \cdot 6$ & $39 \cdot 6$ & $41 \cdot 0$ & $34 \cdot 7$ & $38 \cdot 1$ & $36 \cdot 5$ \\
\hline \multicolumn{10}{|l|}{ Residential area } \\
\hline Urban & $36 \cdot 2$ & $46 \cdot 2$ & $41 \cdot 3$ & $30 \cdot 6$ & $28 \cdot 4$ & $29 \cdot 5$ & $29 \cdot 9$ & 31.9 & $30 \cdot 9$ \\
\hline Rural & $30 \cdot 0$ & $36 \cdot 6$ & $33 \cdot 4$ & $26 \cdot 4$ & $25 \cdot 8$ & $26 \cdot 1$ & $23 \cdot 9$ & $26 \cdot 2$ & $25 \cdot 1$ \\
\hline
\end{tabular}

${ }^{*}$ Data are weighted to be representative of the Thai population.

are inconsistent with those of Friel et al. ${ }^{(14)}$, in which the largest amounts of fruit and vegetables were consumed by married individuals. The explanation for our results may be indirectly related to the age of the participants. More than half of our single participants were in the younger age group, $15-29$ years, while $\sim 53 \%$ of married and $\sim 70 \%$ of widow/divorced/separated participants were in the age groups of 45-69 and 60-79 years, respectively. The needs for foods and nutrients in the young are higher. Moreover, this younger group may be able to access fruit and vegetables with fewer barriers. Even though the amounts of fruit and vegetable intake varied by marital status, marital status by itself was not an independent predictor of fruit and vegetable intake in our study.

Our data also support earlier findings ${ }^{(14,15,18-20)}$ that fruit and vegetable consumption increases with educational level and monthly household income. In addition, we found a strong independent effect of household income on fruit, vegetable and fruit plus vegetable intake. However, educational level attained was a significant factor merely for fruit intake. Interestingly, location of dwelling - either region or residential area - was related to fruit and vegetable intake. Participants who lived in Bangkok or an urban area ate larger amounts of fruit and vegetables compared with those dwelling in other regions or rural areas. One possible rationalization is associated with the marketing system. The majority of fruit and vegetables are cultivated in rural areas of Thailand. Nevertheless, most of them are transported into the markets of big cities. Consequently, availability, accessibility and variety of fruit and vegetables are higher in the big cities. However, other potential factors causing differences in fruit and vegetable consumption among regions require further investigation.

Our study contains both strengths and limitations. Among its strengths, a stratified multistage cluster probability sampling was used to acquire population-based participants distributed across various sociodemographic categories. Moreover, collected data were then weighted by gender and age group using the Census-based population estimates for 2003 as the reference year for the panel. Therefore, the sample is consequently representative of the Thai population. Furthermore, our sample size is quite large and hence the findings are generalizable to the whole population. 
Table 3 Adjusted odd ratios and $95 \%$ confidence intervals of factors associated with meeting the recommended intake amounts of fruit, vegetables and fruit plus vegetables among 39290 adult participants: Thailand National Health Examination Survey III, January to April 2004

\begin{tabular}{|c|c|c|c|c|c|c|}
\hline \multirow[b]{2}{*}{ Sociodemographic factor } & \multicolumn{2}{|c|}{ Fruit $^{\star}$} & \multicolumn{2}{|c|}{ Vegetables* } & \multicolumn{2}{|c|}{ Fruit plus vegetables* } \\
\hline & OR & $95 \% \mathrm{Cl}$ & OR & $95 \% \mathrm{Cl}$ & OR & $95 \% \mathrm{Cl}$ \\
\hline \multicolumn{7}{|l|}{ Gender } \\
\hline Men & $1 \cdot 00$ & ref & - & - & $1 \cdot 00$ & ref \\
\hline Women & 1.46 & $1 \cdot 30,1 \cdot 65$ & - & - & $1 \cdot 13$ & $1 \cdot 01,1 \cdot 27$ \\
\hline \multicolumn{7}{|l|}{ Age (years) } \\
\hline $15-29$ & $1 \cdot 00$ & ref & $1 \cdot 00$ & ref & $1 \cdot 00$ & ref \\
\hline $30-44$ & 0.93 & $0 \cdot 82,1 \cdot 05$ & $1 \cdot 07$ & $0.94,1.23$ & 0.92 & $0 \cdot 81,1 \cdot 04$ \\
\hline $45-59$ & 0.91 & $0.79,1.06$ & 1.05 & $0.92,1.20$ & $0 \cdot 87$ & $0.76,0.99$ \\
\hline $60-69$ & $0 \cdot 85$ & $0.72,0.99$ & $0 \cdot 82$ & $0.71,0.94$ & $0 \cdot 80$ & $0.69,0.93$ \\
\hline $70-79$ & $0 \cdot 77$ & $0.66,0.91$ & $0 \cdot 66$ & $0.56,0.79$ & $0 \cdot 70$ & $0.59,0.84$ \\
\hline$\geq 80$ & $0 \cdot 68$ & $0.53,0.86$ & 0.59 & $0 \cdot 45,0.77$ & $0 \cdot 69$ & $0.53,0.89$ \\
\hline \multicolumn{7}{|l|}{ Educational level } \\
\hline No formal education & $1 \cdot 00$ & ref & - & - & - & - \\
\hline Elementary school & 1.07 & $0.92,1 \cdot 25$ & - & - & - & - \\
\hline Secondary/vocation school & $1 \cdot 42$ & $1 \cdot 20,1 \cdot 69$ & - & - & - & - \\
\hline University & $1 \cdot 29$ & $1 \cdot 04,1 \cdot 60$ & - & - & - & - \\
\hline \multicolumn{7}{|l|}{ Household income (Baht/month) } \\
\hline$<10000$ & 1.00 & ref & 1.00 & ref & 1.00 & ref \\
\hline $10000-24999$ & $1 \cdot 25$ & $1 \cdot 14,1 \cdot 37$ & $1 \cdot 12$ & $1 \cdot 01,1 \cdot 23$ & $1 \cdot 21$ & $1 \cdot 12,1 \cdot 32$ \\
\hline $25000-49999$ & 1.53 & $1 \cdot 32,1 \cdot 78$ & $1 \cdot 32$ & $1 \cdot 12,1 \cdot 56$ & $1 \cdot 40$ & $1 \cdot 20,1 \cdot 63$ \\
\hline$\geq 50000$ & $1 \cdot 60$ & $1 \cdot 30,1 \cdot 98$ & $1 \cdot 45$ & $1 \cdot 17,1 \cdot 80$ & $1 \cdot 66$ & $1 \cdot 29,2 \cdot 12$ \\
\hline \multicolumn{7}{|l|}{ Region } \\
\hline Central & $1 \cdot 00$ & ref & $1 \cdot 00$ & ref & 1.00 & ref \\
\hline North-east & $0 \cdot 61$ & $0 \cdot 48,0 \cdot 76$ & $0 \cdot 76$ & $0.54,1.07$ & $0 \cdot 61$ & $0 \cdot 46,0 \cdot 81$ \\
\hline North & 0.85 & $0.72,1 \cdot 01$ & 0.99 & $0.74,1.33$ & 0.94 & $0.73,1.22$ \\
\hline South & $1 \cdot 22$ & $1 \cdot 01,1 \cdot 47$ & $0 \cdot 72$ & $0.58,0.89$ & 0.92 & $0 \cdot 73,1 \cdot 16$ \\
\hline Bangkok & 0.85 & $0 \cdot 71,1 \cdot 02$ & 1.52 & $1 \cdot 27,1 \cdot 82$ & $1 \cdot 11$ & $0.92,1.34$ \\
\hline \multicolumn{7}{|l|}{ Residential area } \\
\hline Urban & $1 \cdot 00$ & ref & - & - & 1.00 & ref \\
\hline \multirow[t]{2}{*}{ Rural } & $0 \cdot 86$ & $0.78,0.94$ & - & - & $0 \cdot 90$ & $0.81,0.99$ \\
\hline & \multicolumn{2}{|c|}{$\begin{array}{c}n 35603 ; F(17,9)=6.33 \\
P=0.004\end{array}$} & \multicolumn{2}{|c|}{$\begin{array}{c}n 35810 ; F(12,14)=11 \cdot 75 \\
P<0 \cdot 000\end{array}$} & \multicolumn{2}{|c|}{$\begin{array}{c}n \text { 35.810; } F(14,12)=5.04 \\
P=0.004\end{array}$} \\
\hline
\end{tabular}

ref, referent category.

${ }^{*}$ Final models of logistic regression.

Limitations should also be stated. First, the findings are based on a short form of dietary assessment. Although types of fruit and vegetable (i.e. canned or processed fruit or vegetable) were asked, only pictures of whole fruits and vegetables were illustrated. Details about the type and variety of fruits and vegetables typically consumed by this population are therefore unknown. Second, even if it is useful to assess the eating habits among the large sample group, the short FFQ used, combined with pictorial sheets of only one serving size of fruits and vegetables, may cause the under- or overestimation of intake. However, this dietary assessment tool was validated in a sample group which had the same characteristics as the participants. A third limitation is related to self-report. Reliability and validity of self-reported information commonly depend on participants' honesty. Another limitation involved the study design. A cross-sectional design was applied in our study wherein data were collected at only one point in time, so no inferences can be made regarding the chronological sequence of the associations observed here.

Multiple public health benefits of the fruit and vegetable intake recommendation are obvious. However, inadequate fruit and vegetable intake has been found in the majority of Thais. Additional efforts are thus necessary to improve fruit and vegetable consumption, especially for those with advanced age. Effective new strategies and campaigns for promoting fruit and vegetable intake are required. Future research should scrutinize the influence of lifestyle, regions and health-related behaviour differences on fruit and vegetable consumption.

\section{Acknowledgements}

The current study was funded by the Health Systems Research Institute of Thailand. There are no conflicts of interest. W.S. contributed to the completed data analyses, writing of the first draft of the manuscript and revision of the manuscript. W.A. and M.P. contributed to the design of the study, data analyses and revision of the manuscript. All authors were involved in the development of the manuscript and approved the final version. NHESIII was supported by the Bureau of Policy and Strategy, Ministry of Public Health and conducted by the Health Systems Research Institute, Thailand. The authors express their sincere gratitude to all participants for their contribution 
and the NHESIII researcher team whose cooperation made the study possible. Finally, the authors wish to thank Professor Amnuay Thithapandha for his kind help with the English editing of the manuscript.

\section{References}

1. Hung HC, Joshipura KJ, Jiang R, Hu FB, Hunter D, SmithWarner SA, Colditz GA, Rosner B, Spiegelman D \& Willett WC (2004) Fruit and vegetable intake and risk of major chronic disease. J Natl Cancer Inst 96, 1577-1584.

2. Djoussé L, Arnett DK, Coon H, Province MA, Moore LL \& Ellison RC (2004) Fruit and vegetable consumption and LDL cholesterol: the National Heart, Lung, and Blood Institute Family Heart study. Am J Clin Nutr 79, 213-217.

3. Pavia M, Pileggi C, Nobile CGA \& Angelillo IF (2006) Association between fruit and vegetable consumption and oral cancer: a meta-analysis of observational studies. $A m \mathrm{~J}$ Clin Nutr 83, 1126-1134.

4. Ahn J, Gammon MD, Santella RM et al. (2005) Associations between breast cancer risk and catalase genotype, fruit and vegetable consumption, and supplement use. $A m J$ Epidemiol 162, 943-952.

5. Michels KB, Giovannucci E, Chan AT, Singhania R, Fuchs CS \& Willett WC (2006) Fruit and vegetable consumption and colorectal adenomas in the Nurses' Health Study. Cancer Res 66, 3942-3953

6. Genkinger JM, Platz EA, Hoffman SC, Comstock GW \& Helzlsouer KJ (2004) Fruit, vegetable, and antioxidant intake and all-cause, cancer, and cardiovascular disease mortality in a community-dwelling population in Washington County, Maryland. Am J Epidemiol 160, 1223-1233.

7. Christen WG, Liu S, Schaumberg DA \& Buring JE (2005) Fruit and vegetable intake and the risk of cataract in women. Am J Clin Nutr 81, 1417-1422.

8. Pomerleau J, Lock K \& McKee M (2006) The burden of cardiovascular disease and cancer attributable to low fruit and vegetable intake in the European Union: differences between old and new member states. Public Health Nutr 9 , 575-583.

9. World Health Organization (2002) The World Health Report 2002: Reducing Risks, Promoting Healthy Life. Geneva: WHO.

10. Pomerleau J, Lock K, McKee M \& Altmann DR (2004) The challenge of measuring global fruit and vegetable intake. J Nutr 134, 1175-1180.

11. Department of Health, Ministry of Public Health, School of Public Health, Mahidol University (1995) The Third National Nutrition Survey of Thailand, 1986. Bangkok: The War Veterans Organization of Thailand.
12. Department of Health, Ministry of Public Health (1996) The Fourth National Nutrition Survey of Thailand, 1995. Bangkok: Ministry of Public Health.

13. World Health Organization (2003) Fruit and Vegetable Promotion Initiative: A Meeting Report, Geneva, 25-27 August 2003. Geneva: WHO.

14. Friel S, Newell J \& Kelleher C (2005) Who eats four or more servings of fruit and vegetables per day? Multivariate classification tree analysis of data from the 1998 survey of lifestyle, attitudes and nutrition in the Republic of Ireland. Public Health Nutr 8, 159-169.

15. Shohaimi S, Welch A, Bingham S, Luben R, Day N, Wareham N \& Khaw KT (2004) Residential area deprivation predicts fruit and vegetable consumption independently of individual educational level and occupational social class: a cross sectional population study in the Norfolk cohort of the European Prospective Investigation into Cancer (EPIC-Norfolk). J Epidemiol Community Health 58, 686-691.

16. Thompson RL, Margetts BM, Speller VM \& McVey D (1999) The Health Education Authority's health and lifestyle survey 1993: who are the low fruit and vegetable consumers? J Epidemiol Community Health 53, 294-299.

17. Li R, Serdula M, Bland S, Mokdad A, Bowman B \& Nelson D (2000) Trends in fruit and vegetable consumption among adults in 16 US states: behavioral risk factors surveillance system, 1990-1996. Am J Public Health 90, 777-781.

18. O'Brien MM, Kiely M, Galvin M \& Flynn A (2003) The importance of composite foods for estimates of vegetable and fruit intakes. Public Health Nutr 6, 711-726.

19. Giskes K, Turrell G, Patterson C \& Newman B (2002) Socioeconomic differences in fruit and vegetable consumption among Australian adolescents and adults. Public Health Nutr 5, 663-669.

20. Ball K, Crawford D \& Mishra G (2006) Socioeconomic inequalities in women's fruit and vegetable intakes: a multilevel study of individual, social and environmental mediators. Public Health Nutr 9, 623-630.

21. Aekplakorn W, Abbott-Klafter J, Premgamone A, Dhanamun B, Chaikittiporn C, Chongsuvivatwong V, Suwanprapisa T, Chaipornsupaisan W, Tiptaradol S \& Lim SS (2007) Prevalence and management of diabetes and associated risk factors by regions of Thailand: Third National Health Examination Survey 2004. Diabetes Care 30, 2007-2012.

22. Serdula M, Coates R, Byers T et al. (1993) Evaluation of a brief telephone questionnaire to estimate fruit and vegetable consumption in diverse study populations (abstract). Epidemiology 4, 455-463.

23. Andersen LF, Johansson L \& Solvoll K (2002) Usefulness of a short food frequency questionnaire for screening of low intake of fruit and vegetable and for intake of fat. Eur J Public Health 12, 208-213. 